CASE REPORT

\title{
Antithyroid arthritis syndrome
}

\author{
Anar Modi, ${ }^{1}$ Hari Amin, ${ }^{2}$ Farah Morgan ${ }^{1}$
}

${ }^{1}$ Department of Endocrinology, Cooper University Hospital, Camden, New Jersey, USA ${ }^{2}$ Department of Emergency Medicine, Cooper University Hospital, Camden, New Jersey, USA

\section{Correspondence to}

Dr Anar Modi, modi-anar@ cooperhealth.edu

Accepted 14 February 2017

\section{SUMMARY}

Antithyroid arthritis syndrome is a constellation of symptoms of myalgia, arthralgia, arthritis, fever and rash associated with the use of antithyroid medications. We report a case of a patient with severe hyperthyroidism likely secondary to Graves' disease who presented with the abovementioned symptoms after being treated with methimazole (antithyroid medication). Our aim is to increase awareness regarding this uncommon but disabilitating and life-threatening adverse effect of antithyroid medications among clinicians. We also discuss the proposed pathophysiology for this immunological reaction as well as management options in these patients.

\section{BACKGROUND}

Antithyroid medications like methimazole and propylthiouracil are commonly used in the treatment of hyperthyroidism. Most common adverse effects noted with these agents are skin eruptions and the most serious but well-known adverse effects are agranulocytosis and acute liver toxicity. One of the rare side effects of this class of medications is antithyroid arthritis syndrome which has been reported in the case described below.

\section{CASE PRESENTATION}

A Caucasian woman aged 50 years presented with fever, palpitations, anxiety and severe arthralgia of 5 -day duration. One month prior, she was diagnosed with hyperthyroidism and was started on methimazole $20 \mathrm{mg}$ three times a day along with metoprolol $25 \mathrm{mg}$ two times per day. This treatment partially alleviated her symptoms until 5 days prior to the aforementioned presentation.

On arriving at the emergency room, she reported fever of $103^{\circ} \mathrm{F}$, palpitations and anxiety along with severe joint pain and rash over her joints. She described sharp, constant pain in her hands, wrists, shoulders, knees and ankles that worsened with movement and touch. She had no pain relief with ibuprofen. The patient denied any personal or family history of autoimmune or thyroid disease and also denied any tobacco, alcohol or drug use. Family history was only significant for breast cancer and hypertension in her mother. Vitals signs revealed blood pressure of $163 / 79 \mathrm{~mm} / \mathrm{Hg}$, pulse of $120 \mathrm{bpm}$, temperature of $101.3^{\circ} \mathrm{F}$ and oxygen saturation of $92 \%$ on room air. She was thin, anxious appearing, diaphoretic and appeared to be in moderate distress. Extraocular movements were intact. She had mild proptosis and chemosis. Thyroid examination revealed a bilaterally enlarged firm and non-tender thyroid gland without nodules or bruit. She had a fine tremor to outstretched hands.
Cardiopulmonary examination was significant only for sinus tachycardia. Musculoskeletal examination demonstrated decreased range of motion in the bilateral upper and lower extremities with swelling, warmth, erythema and tenderness in multiple joints, including the knee, ankle, hand and wrist.

\section{INVESTIGATIONS}

Her initial labs showed thyroid-stimulating hormone $<0.01 \mathrm{IU} / \mathrm{mL} \quad(0.27-4.20)$, free $\mathrm{T} 4$ $3.7 \mathrm{ng} / \mathrm{dL}(0.8-1.8)$ and free $\mathrm{T} 36.4 \mathrm{pg} / \mathrm{mL}(2.0$ 4.4). Blood cultures, urinalysis and urine culture, which were ordered in the setting of mild leucocytosis and fever, were negative for infection. The patient's biochemical profile showed a normal renal function and liver function. Erythrocyte sedimentation rate was $67 \mathrm{~mm} /$ hour $(0-20)$ and $C$ reactive protein $20.16 \mathrm{mg} / \mathrm{dL} \quad(<0.50)$. Autoimmune workup was pursued which revealed negative antinuclear antibody (ANA) screen, myeloperoxidase antibody was $<1.0(<1.0)$, proteinase 3 antibody $<1.0 \quad(<1.0)$, anticyclic citrullinated peptide (anti-CCP AB IGG) <16 arb'U (<20), antidoublestranded DNA antibody (anti-ds DNA) $14 \mathrm{IU} / \mathrm{mL}$ $(<100)$, antihistone antibody $<1.0 \mathrm{U}(<1.0)$, HLA B27 negative, rheumatoid factor (RF) negative, anti-RO antibody $($ SSA $)<1.0(<1.0)$ and anti-LA antibody (SSB) $<1.0(<1.0)$. Only C-ANCA (antineutrophil cytoplasmic antibody) was positive with a titre of $1: 20(<1: 20)$.

Ultrasound of thyroid showed a bilaterally enlarged thyroid gland with increased blood flow throughout the gland and no discrete nodules.

\section{TREATMENT}

Owing to concern for thyroid storm on admission, she was started on dexamethasone $2 \mathrm{mg}$ every 6 hours intravenously, propylthiouracil (PTU) $250 \mathrm{mg}$ every 6 hours orally (methimazole was discontinued) and propranolol $60 \mathrm{mg}$ every 6 hours. The following day her steroids were switched to prednisone $60 \mathrm{mg}$ daily. During her hospital stay, she was noted to have migratory polyarthritis and hence steroids were continued. Over the next couple of weeks, she showed clinical as well as biochemical improvement and was discharged on prednisone $30 \mathrm{mg}$ oral tablets, two times a day to be tapered over the next 10 weeks, PTU $150 \mathrm{mg}$ oral tablets three times a day and propranolol $60 \mathrm{mg}$ three times a day.

\section{OUTCOME AND FOLLOW-UP}

One month after hospitalisation, the patient was seen in outpatient endocrine clinic. She was symptom-free while on PTU and tapering doses of prednisone. Definitive treatment options of 
radioactive iodine ablation versus total thyroidectomy were discussed with the patient for a presumptive diagnosis of Graves' disease. Total thyroidectomy is being considered due to concern of worsening Graves' eye disease.

\section{DISCUSSION}

Transient migratory polyarthritis secondary to the use of antithyroid medications has been reported in the literature as an uncommon side effect of this therapy. The constellation of symptoms of myalgias, arthralgias and arthritis along with fever and rash is known as antithyroid arthritis syndrome. ${ }^{1} 2$ PTU and methimazole are thioureylene derivatives commonly used in the management of hyperthyroidism. In a review of 500 patients managed with antithyroid drugs, rheumatic symptoms were noted in $1.6 \%$ of cases which was only second to skin eruptions. ${ }^{2}$ Another review of the literature noted 53 cases of immunological side effects with the use of antithyroid drugs over a 35 -year period. ${ }^{3}$ It was also noted that the reactions occurred at any age, were predominant in females, noted at any dosage and at any time during therapy. ${ }^{4-6}$ As per Cooper, ${ }^{7}$ side effects of methimazole are dose-dependent, but there is no dose relationship for PTU.

In most cases of antithyroid arthritis syndrome, the first symptom is arthralgia. ${ }^{8} 9$ It often develops within 2 months after initiation of antithyroid treatment but can occur at any time. It may quickly progress to a full-blown polyarthritis involving large, medium and small joints. ${ }^{10}$ The other rheumatic symptoms noted in the literature in association with antithyroid drugs include lupus-like syndrome, polymyositis, polyarteritis nodosum and life-threatening ANCA-positive vasculitis. ${ }^{11-13}$

The proposed theories by which the thionamides cause immunological reactions are:

1. Thionamides and its metabolites are taken up by neutrophils where they bind to myeloperoxidase and turn it and other proteins like lactoferrin, elastase, etc, immunogenic. ${ }^{14} 15$

2. Individuals with a deficit in cellular copper-binding capacity have excess free copper, which then binds to antithyroid drugs. This complex affects glutathione metabolism with resultant release of interleukins and synovial inflammation. ${ }^{16}$

3. Thiol group in antithyroid drugs binds to macromolecules and serves as haptan and induces antibody production. ${ }^{3}$

4. Metabolites of PTU may compete with thymidine triphosphatase and inhibit the DNA synthesis or be incorporated in DNA, triggering an abnormal immune function. ${ }^{3}$

It has also been suggested that patients with antithyroid arthritis may be predisposed to developing rheumatoid arthritis. ${ }^{17}$

Awareness of this syndrome is necessary for prompt diagnosis. Routine monitoring of laboratory values is not helpful. Low complement levels and elevated $\gamma$ globulin suggest an immune complex mechanism. Positive ANA has been reported, but its prevalence in antithyroid medication-treated population was no greater than in the control population. ${ }^{18}$ Gao et $a l^{19}$ studied the presence of ANCA and noted that 2.9\% of untreated patients with Graves' disease were ANCA-positive and 22\% of patients treated with PTU were ANCA-positive. Antihistone antibody, anti-ds-DNA, anti-SSA/SSB antibodies, RF, anti-CCP AB, antimyeloperoxidase antibody, antiproteinase 3 antibodies, antielastase, antilactoferrin and anticathepsin are among other antibodies shown to be associated with antithyroid therapy-induced immunological adverse effects. ${ }^{13}$ Creatinine phosphokinase elevation has been reported in the literature with PTU-induced polymyositis. ${ }^{12}$ In our patient, all immunological workup was negative except C-ANCA which was only mildly elevated. It is uncertain if this is related to her underlying
Graves' disease or secondary to methimazole treatment. In the series of 500 patients studied by Shabtai et al, ${ }^{2}$ the majority of patients who developed rheumatological symptoms had no immunological evidence on laboratory which could explain the negative immunological workup in our patient.

The first step in treatment of this syndrome is discontinuation of the antithyroid medication. For mild to moderate symptoms, non-steroidal anti-inflammatory drug can be used. The benefit of corticosteroid therapy is uncertain, but it is recommended for life-threatening or unresolving adverse effects. The suggested dose of prednisone is $0.5-1 \mathrm{mg} / \mathrm{kg}$ of prednisone. ${ }^{3}$ Our patient was started on high-dose dexamethasone due to concern for thyroid storm. This was later switched to prednisone as migratory polyarthritis was noted. Methimazole was discontinued and switched to PTU. Though, due to cross-reactivity between different thionamides in vitro, ${ }^{20}$ it is advisable to consider alternative treatment if possible when side effects of thionamides occur. Our patient fortunately tolerated PTU and had no further adverse effects. In this case, thyroidectomy is being considered as a definitive treatment due to concern of worsening Graves' ophthalmopathy with radioactive iodine ablation treatment.

In conclusion, the antithyroid arthritis syndrome is a rare complication of antithyroid medications. Variability in its severity, and non-specific laboratory findings, make its diagnosis challenging. Once the diagnosis is made, it requires immediate discontinuation of the offending drug as it can rapidly progress to a life-threatening condition. Optimal management of this condition requires better understanding of the immunological process leading to antithyroid arthritis syndrome.

\section{Learning points}

- High index of suspicion for signs and symptoms of antithyroid arthritis syndrome in patients on antithyroid medications is needed for early recognition and treatment of the disease as delay in the management can lead to life-threatening complications.

- Discontinuation of the offending drug results in resolution of the symptoms.

- Cross-reactivity is noted among different antithyroid medications and hence caution is warranted in the use of alternative medications from the same thioureylene group.

Contributors AM is the corresponding author and contributed in writing the case, literature review and writing the discussion. HA contributed in literature search and writing the manuscript. FM is the attending endocrinologist who reviewed the manuscript and made necessary changes to it.

Competing interests None declared.

\section{Patient consent Obtained.}

Provenance and peer review Not commissioned; externally peer reviewed.

\section{REFERENCES}

1 Bajaj S, Bell MJ, Shumak S, et al. Anti-thyroid arthritis syndrome. J Rheumatol 1998;25:1235-9.

2 Shabtai R, Shapiro MS, Orenstein D, et al. The anti-thyroid arthritis syndrome reviewed. Arthritis Rheum 1984;27:227-9.

3 Wing SS, Fantus IG. Adverse immunologic effects of antithyroid drugs. CMAJ 1987;136:121-7.

4 Searle RP, Plymate SR, Troup GM. Familial thionamide induced lupus syndrome in thyrotoxicosis. J Rheumatol 1981;8:498-500.

5 Richard A, Walzer MD, Julia Einbinder MS. Immunoleukopenia as an aspect of hypersensitivity to propylthiouracil. JAMA 1963;184:743-6. 
6 Cassorla FG, Finegold DN, Parks JS, et al. Vasculitis, pulmonary cavitation, and anemia during anti-thyroid drug therapy. Am J Dis Child 1983;137:118-22.

7 Cooper DS. The side effects of anti-thyroid drugs. Endocrinologist 1999;9:457-76.

8 Tan F, Nam TQ, Lee KO, et al. Recurrent episodes of arthritis in a hyperthyroid patient. Singapore Med J 2006;47:163-5.

9 Morita S, Ueda Y, Eguchi K. Anti-thyroid drug-induced ANCA-associated vasculitis: a case report and review of the literature. Endocr I 2000;47:467-70.

10 Ploegstra WM, Boontje RP, Kamps AWA. Arthritis associated with anti-thyroid therapy in a 15-year-old girl. J Pediatr Pharmacol Ther 2011;16:98-101.

11 Prasad GV, Bastacky S, Johnson JP. Propylthiouracil-induced diffuse proliferative lupus nephritis: review of immunological complications. I Am Soc Nephrol 1997;8:1205-10.

12 Sherby WJ, Caldwell DS. Polymyositis after propylthiouracil treatment for hyperthyroidism. Ann Rheum Dis 1988;47:340-3.

13 Aloush V, Litinsky I, Caspi D, et al. Propylthiouracil-induced autoimmune syndromes: two distinct clinical presentations with different course and management. Semin Arthritis Rheum 2006;36:4-9.
14 Jiang, X., Khursigara, G., Rubin, RL. Transformation of lupus-inducing drugs to cytotoxic products by activated neutrophils. Science 1994;266: 810-13.

15 Waldhauser L, Uetrecht J. Antibodies to myeloperoxidase in propylthiouracil-induced autoimmune disease in the cat. Toxicology 1996;114:155-62.

16 Rafter GW. Methimazole and arthritis. Scand I Rheumatol 1990;19:385.

17 Farbman K, Wheeler M, Glick S. Arthritis induced by antithyroid medication. NY State J Med; 1969 Mar 15;69:826-31.

18 Centina JA, Fishbein E, Alarcon-Segovia D. Antinuclear antibodies and propylthiouracil therapy. JAMA 1972;220:1012.

19 Gao Y, Zhao MH, Guo XH, et al. The prevalence and target antigens of anti-thyroid drugs induced antineutrophil cytoplasmic antibodies (ANCA) in Chinese patients with hyperthyroidism. Endocr Res 2004;30:205-13.

20 Wall JR, Fang SL, Kuroki T, et al. In vitro immunoreactivity to propylthiouracil, methimazole, and carbimazole in patients with Graves' disease: a possible cause of anti-thyroid drug-induced agranulocytosis. I Clin Endocrinol Metab 1984;58:868-72.

Copyright 2017 BMJ Publishing Group. All rights reserved. For permission to reuse any of this content visit http://group.bmj.com/group/rights-licensing/permissions.

BMJ Case Report Fellows may re-use this article for personal use and teaching without any further permission.

Become a Fellow of BMJ Case Reports today and you can:

- Submit as many cases as you like

- Enjoy fast sympathetic peer review and rapid publication of accepted articles

- Access all the published articles

- Re-use any of the published material for personal use and teaching without further permission

For information on Institutional Fellowships contact consortiasales@bmjgroup.com

Visit casereports.bmj.com for more articles like this and to become a Fellow 